

\title{
High PTGS2 expression in post neoadjuvant chemotherapy treated oesophageal adenocarcinoma is associated with improved survival: a population-based cohort study
}

Spence, A. D., Trainor, J., McMenamin, Ú., Turkington, R. C., McQuaid, S., Bingham, V., James, J., SaltoTellez, M., McManus, D. T., Johnston, B. T., Cardwell, C. R., \& Coleman, H. G. (2019). High PTGS2 expression in post neoadjuvant chemotherapy treated oesophageal adenocarcinoma is associated with improved survival: a population-based cohort study. Histopathology, 74(4), 587-596. https://doi.org/10.1111/his.13786

Published in:

Histopathology

Document Version:

Peer reviewed version

Queen's University Belfast - Research Portal:

Link to publication record in Queen's University Belfast Research Portal

\section{Publisher rights}

Copyright 2018 Wiley. This work is made available online in accordance with the publisher's policies. Please refer to any applicable terms of use of the publisher.

\section{General rights}

Copyright for the publications made accessible via the Queen's University Belfast Research Portal is retained by the author(s) and / or other copyright owners and it is a condition of accessing these publications that users recognise and abide by the legal requirements associated with these rights.

Take down policy

The Research Portal is Queen's institutional repository that provides access to Queen's research output. Every effort has been made to ensure that content in the Research Portal does not infringe any person's rights, or applicable UK laws. If you discover content in the

Research Portal that you believe breaches copyright or violates any law, please contact openaccess@qub.ac.uk. 


\section{Title}

High PTGS2 expression in post neoadjuvant chemotherapy treated oesophageal adenocarcinoma is associated with improved survival: a population-based cohort study

\section{Short title}

PTGS2 expression and oesophageal cancer survival

\section{Authors}

Andrew D Spence ${ }^{\mathrm{a}}$, James Trainor ${ }^{\mathrm{b}}$, Úna McMenamin ${ }^{\mathrm{a}}$, Richard C Turkington ${ }^{\mathrm{c}}$, Stephen McQuaid ${ }^{\mathrm{d}}$, Victoria Bingham ${ }^{\mathrm{d}}$, Jacqueline James ${ }^{\mathrm{d}}$, Manuel Salto-Tellez ${ }^{\mathrm{d}}$, Damian T McManus ${ }^{\mathrm{b}}$, Brian T Johnston ${ }^{\mathrm{e}}$, Chris R Cardwell ${ }^{\mathrm{a}}$, Helen G Coleman ${ }^{\mathrm{a}, \mathrm{c}}$

\section{Authors' affiliations}

${ }^{\mathrm{a} C a n c e r}$ Epidemiology and Health Services Research Group, Centre for Public Health, Queen’s University Belfast, Belfast, Northern Ireland, United Kingdom ${ }^{b}$ Department of Pathology, Belfast Health and Social Care Trust, Belfast, Northern Ireland, United Kingdom

${ }^{\mathrm{c} C e n t r e}$ for Cancer Research and Cell Biology, Queen's University Belfast, Belfast, Northern Ireland, United Kingdom

${ }^{\mathrm{d}}$ Northern Ireland Molecular Pathology Laboratory, Centre for Cancer Research and Cell Biology, Queen's University Belfast, Belfast, Northern Ireland, UK.

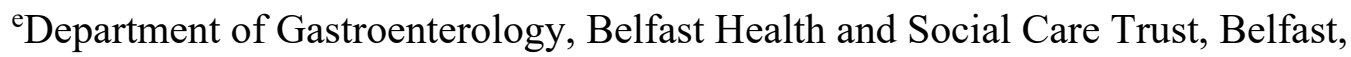
Northern Ireland, United Kingdom 
Correspondence to: Dr Andrew Spence MSc, MRCP, Gastroenterologist, Institute of Clinical Sciences Block B, Queen's University Belfast, Royal Victoria Hospital, Belfast, Northern Ireland, BT12 6BA.

Telephone: +44 (0) 2890635009

Fax: $+44(0) 2890235900$

Email: aspence04@qub.ac.uk

\section{Conflicts of Interest}

The authors have no conflicts of interest. 


\title{
ABSTRACT
}

\begin{abstract}
Aims
High prostaglandin endoperoxide synthase-2 (PTGS2) enzyme expression in oesophageal adenocarcinoma has been shown to independently predict poor prognosis, however evidence is inconsistent. We investigated the association between PTGS2 expression and prognosis in patients with oesophageal adenocarcinoma.
\end{abstract}

\section{Methods and results}

A cohort of 135 patients with oesophageal adenocarcinoma who received neoadjuvant chemotherapy and surgery from 2004 to 2012 was identified in the Northern Ireland Cancer Centre. Tissue microarrays were created in the Northern Ireland Biobank, sampling triplicate cores from each tumour. Immunohistochemical PTGS2 expression was scored by two independent assessors with intensity and proportion of tumour staining used to calculate $\mathrm{H}$-scores for each patient. Cox regression models were used to calculate hazard ratios (HR) and $95 \%$ confidence intervals (95\% CIs) for overall and cancer-specific survival, and recurrence-free survival by PTGS2 expression, adjusting for potential confounders.

Patients were followed up for a mean of 3.0 (SD 1.8) years. The PTGS2 expression cut-off value was determined using the median H-score of the cohort (270/300). High $(n=79)$, compared to low ( $\mathrm{n}=56)$, PTGS2 expression was associated with improved cancer-specific survival (adjusted HR 0.56, 95\% CI 0.33-0.94; $\mathrm{p}=0.03$ ). PTGS2 expression was not significantly associated with recurrence-free survival (adjusted HR 0.85, 95\% CI 0.52-1.38; $\mathrm{p}=0.51$ ). 


\section{Conclusions}

High PTGS2 expression in oesophageal adenocarcinoma tissue was associated with improved overall and cancer-specific survival, contrasting previous evidence. As this is the first study of its kind to include patients who had undergone neoadjuvant chemotherapy further studies are needed to clarify these associations.

Keywords: Oesophageal cancer; PTGS2 expression; Survival; Epidemiology; Biomarker 


\section{Introduction}

Oesophageal cancer is the eighth most common cancer worldwide, ${ }^{1}$ with a poor prognosis (15\% five-year survival rate in the United Kingdom²). As survival from this cancer remains poor, new treatments to supplement chemotherapy, radiotherapy and surgery are being investigated, including using commonly prescribed medications, such as aspirin. ${ }^{3}$ There is also increasing interest in the development of prognostic biomarkers, which could facilitate these treatment decisions.

Preclinical research has shown prostaglandin endoperoxide synthase-2 (PTGS2, also known as cyclooxygenase-2 or COX-2) enzyme activity is associated with inflammation and tumour growth, a potential prognostic biomarker. ${ }^{4}$ The PTGS2 enzyme converts arachidonic acid to prostaglandins and other eicosanoids, which can induce carcinogenesis through enhanced inflammatory changes and cellular proliferation. ${ }^{5}$ High PTGS2 expression is associated with additional carcinogenic processes including increased intratumoural microvessel density and reduced apoptosis. $^{6,7}$ Specifically, oesophageal cancer cells are known to have greater expression of PTGS2, compared with normal tissue. ${ }^{8-10}$

Although the association between PTGS2 enzyme expression in oesophageal squamous cell carcinoma tissue and survival has been extensively studied, ${ }^{11}$ few studies have investigated the adenocarcinoma subtype. Moreover, results are inconsistent with four ${ }^{12-15}$ of the seven studies finding PTGS2 expression was not associated with survival, whereas the remaining three ${ }^{16-18}$ studies found survival was worse with high PTGS2 expression. Furthermore, only two studies have investigated 
cancer-specific survival outcomes, one finding high PTGS2 expression was associated with decreased overall but not cancer-specific survival, ${ }^{14}$ and the other showing no association for either outcome. ${ }^{12}$ Also, all previous studies of oesophageal adenocarcinoma excluded patients who underwent chemotherapy, now a standard component of management. Further studies are needed to help clarify the association between PTGS2 expression and survival in patients with oesophageal adenocarcinoma.

The aim of this study was to investigate the association between PTGS2 expression and survival outcomes in a cohort of patients diagnosed with oesophageal adenocarcinoma who underwent neoadjuvant chemotherapy.

\section{Materials \& methods}

\section{Data sources}

Clinical data for this study were obtained from the Northern Ireland Cancer Centre electronic Clinical Oncology Information System (COIS). Tissue specimens were obtained from the Northern Ireland Biobank. This biobank contains tissue samples obtained from regional Health Trust pathology departments for use in research. ${ }^{19}$ It has ethical approval from the Office for Research Ethics Committees Northern Ireland (ORECNI, reference: 16/NI/0030) to obtain, store and distribute samples for research purposes. The Northern Ireland Biobank granted approval for this study (study number NIB15-0176). 
Study design and cohort

Individuals with newly diagnosed oesophageal cancer between 2004 and 2012 were identified in the Northern Ireland Cancer Centre database. The cohort was restricted to all patients with non-metastatic oesophageal adenocarcinoma who underwent surgical resection following neoadjuvant chemotherapy. The Northern Ireland Biobank retrieved oesophageal adenocarcinoma resection specimens for these patients from the archives, creating a population-representative cohort. Patients were excluded from the analysis if there were no tumour cells present in their tissue samples or if clinicopathological data were insufficient. Oesophageal all-cause and cancer-specific deaths (primary cause of death recorded as oesophageal or gastric cancer) were identified from the vital statistics in the COIS and follow-up began from the date of oesophageal adenocarcinoma diagnosis. Patients were followed-up until their last review appointment, date of recurrence, date of death or end of study follow-up ( $31^{\text {st }}$ December 2014). Overall survival was defined as survival until death from any cause, whereas cancer-specific survival was defined as survival time until death where the primary cause was oesophageal adenocarcinoma. Tumour recurrence was defined as development of local or distant cancer during follow-up. Recurrence-free survival was defined as time from the start of follow-up until diagnosed with a recurrence or death from any cause. The study has been reported in accordance with the REMARK recommendations (Supplementary Table 1). ${ }^{20}$

\section{TMA construction}

A tissue microarray (TMA) was created in the Northern Ireland Biobank, including three tumour cores from each patient's surgical resection specimen. A detailed 
description of TMA construction methods within the Northern Ireland Biobank is described elsewhere..$^{21,22}$

Immunohistochemical staining procedure

Using an in-house optimised protocol for PTGS2 (Rabbit monoclonal antibody Ventana catalogue number: 760-4254) IHC was performed on TMA sections in the Northern Ireland Molecular Pathology Laboratory. Sections were cut at $4 \mu \mathrm{m}$ on a rotary microtome, dried at $37^{\circ} \mathrm{C}$ overnight, and then used for $\mathrm{IHC}$, which was performed using an automated immunstainer (PTGS2; Cell Conditioning solution 1 for 32 mins, Primary antibody 16mins on Ventana BenchMark, Ventana Medical Systems Inc, Tuscon, AZ). Antigen-binding sites were detected with Optiview detection kit. All sections were visualized with diaminobenzidine, counterstained with hematoxylin, and mounted in DPX. Test tissue with no primary antibody was used as a negative control. Sections were scanned using an Aperio AT2 scanner to be viewed electronically.

\section{Scoring methods}

TMA specimens were reviewed and scored using PathXL electronic image viewer. PTGS2 expression was assessed by two independent observers (ADS and JT) who were blinded to clinical data. Any discordant results were clarified by discussion between ADS, JT and DMcM. Scoring was achieved by determination of the proportion of tumour cells staining positive, calculated as a percentage, and the intensity of cytoplasmic staining (scored $0=$ no staining, $1=$ weak, $2=$ moderate and 3 = strong intensity) (Figure 1). These two values were multiplied to produce an ' $\mathrm{H}$ - 
score' for each core sample, ${ }^{23}$ with minimum and maximum possible scores of 0 and 300 , respectively.

\section{Clinical variables}

Demographic and clinical information included age at diagnosis, sex, date of diagnosis, smoking and alcohol history. The primary tumour location was categorised into lower third of the oesophagus and the gastro-oesophageal junction. The Siewert classification $^{24}$ was used to categorise junctional tumours (1: adenocarcinoma of the distal oesophagus; 2: true carcinoma of the cardia arising at the gastro-oesophageal junction; 3: subcardial gastric cancer infiltrating the distal oesophagus). Response to chemotherapy on positron emission tomography scan (PET responder), circumferential resection margins (CRM) status, tumour grade and lymphatic vascular invasion data were also retrieved. Pathological staging was defined according to the

International Union Against Cancer (UICC) TNM system, $7^{\text {th }}$ Edition. ${ }^{25}$ A Mandard score of $\leq 2$ indicated a pathological response in the resection specimens. Missing categories were formed when there was absence of data (smoking and PET responder).

Statistical analysis

Maximum H-scores from triplicate cores for each patient were used to classify patients according to PTGS2 expression. The maximum H-score of each patient's three cores was selected as their overall H-score. The median value of the cohort's overall H-scores was 270 , which was selected as a cut-off value to define low/high PTGS2 expression. 
Differences between clinical and pathological characteristics by PTGS2 expression were calculated using chi-squared tests. Cox regression models were used to calculate hazard ratios (HRs) and 95\% confidence intervals (95\% CI) for overall and cancerspecific survival according to tumour tissue PTGS2 expression (high versus low). Univariable analysis was first conducted, followed by multivariable analysis which included adjustment for age, smoking history, gender, surgical nodal stage, tumour location, PET responder status, CRM, tumour grade and vascular lymphatic invasion. Adjustment for alcohol consumption and tumour ' $\mathrm{T}$ ' stage was tested but omitted in backwards selection from the final multivariate model due to having limited impact on the results. A positive PET response was defined as greater than or equal to $35 \%$ reduction in the SUVmax of the primary tumour between pre- and post-chemotherapy scans. Associations between tumour PTGS2 expression and recurrence-free survival were also investigated. Additionally, outcomes were investigated in sensitivity analyses restricting the cohort to patients diagnosed with gastro-oesophageal junctional tumours. Events are defined as death from any cause for overall survival, death from oesophageal adenocarcinoma for cancer-specific survival and recurrence or death from any cause in analysis of recurrence-free survival. Analysis was performed using Stata version 14 (StataCorp LP, College Station, TX, USA).

\section{Results}

Patient cohort

A total of 158 patients with oesophageal adenocarcinoma underwent neoadjuvant chemotherapy followed by surgery between 2004 and 2012 in Northern Ireland. 
Fifteen patients were excluded due to absence of tumour in all three core samples and four patients were removed due to lack of clinical and/or pathological data. A further three were excluded due to complete response following neoadjuvant chemotherapy and one patient was removed because there were metastases present at the time of surgery, leaving 135 for the main analysis (Figure 2). The mean follow-up time was 3.0 years (minimum 5 months, maximum 9 years), during which there were 80 deaths, 75 of which due to oesophageal adenocarcinoma, and 78 recurrences.

\section{Patient Characteristics}

Table 1 shows the patient characteristics by PTGS2 expression. The majority of the cohort was male (77\%) and the mean age at diagnosis was 62 years old. The most common tumour site was the gastro-oesophageal junction $(85 \%)$ and $43 \%$ of patients were PET responders. Five patients had pathological response (Mandard $\leq 2$ ), whereas 130 had a Mandard greater than two.

Association of PTGS2 with clinico-pathological variables

High PTGS2 expression was more frequently observed in patients responding to chemotherapy on PET scan. There were no differences between low/high PTGS2 expression and other clinicopathological variables investigated (Table 1). After Bonferroni corrections for multiple comparisons, the difference between the two groups was no longer apparent.

Association between PTGS2 expression and survival

In this cohort, patients with tumours showing high PTGS2 expression had a $43 \%$ reduced risk of death (unadjusted HR 0.61, 95\% CI 0.39, 0.96, adjusted HR 0.57, 
95\% CI 0.34, 0.93) (Table 2). There was a similar association observed for cancerspecific survival, with a $44 \%$ improvement in survival (unadjusted HR $0.62,95 \%$ 0.39, 0.99, adjusted HR 0.56, 95\% CI 0.33, 0.93). PTGS2 expression was not significantly associated with recurrence-free survival (adjusted HR 0.85, 95\% CI 0.52, $1.38)$.

Sensitivity analyses

When restricting the cohort to only those patients with tumours located in the gastrooesophageal junction, high PTGS2 expression was associated with 48\% improved overall and 50\% improved cancer-specific survival (adjusted HR 0.52, 95\% CI 0.300.90 and adjusted HR $0.50,95 \%$ CI $0.28-0.88$, respectively). Similar to the main analysis, there was no significant association between high compared with low PTGS2 expression and recurrence-free survival (adjusted HR 0.71, 95\% CI 0.42-1.21) (Table 3 ). As only $15 \%$ of the tumours were situated in the distal oesophagus, this sensitivity analysis was only conducted on junctional cancers.

\section{Discussion}

In this population-based cohort of patients with oesophageal adenocarcinoma we found PTGS2 expression was associated with improved overall and cancer-specific survival. Although HRs were reduced in analysis of PTGS2 expression and recurrence-free survival, results were not statistically significant. Similar associations to the main analysis were observed when restricting analysis to tumours located at the gastro-oesophageal junction. 
There have been seven previous survival studies of patients with oesophageal adenocarcinoma and PTGS2 expression, ${ }^{12-14,16-18,26}$ however one combined their analysis with oesophageal squamous cell carcinoma cases. ${ }^{26}$ Three of these studies found high PTGS2 expression was associated with poorer overall survival, ${ }^{16-18}$ consistent with a 2017 meta-analysis by $\mathrm{Hu}$ et al. (pooled HR 2.13, 95\% CI 1.622.79). ${ }^{11}$ Of the two previous studies investigating cancer-specific survival, Prins et al. found although PTGS2 expression was an independent predictor of poor overall survival, associations were non-significant in analysis of cancer-specific survival, after adjustment for confounders (HR 1.55, 95\% CI 0.95-2.53). ${ }^{14}$ Similarly, in a study of 66 patients, Lagorce et al. showed PTGS2 expression was not associated with cancer-specific survival. $^{12}$

The differences in improved survival for patients with high PTGS2 expression tumours observed in this study contrast with previous evidence. This may be because all patients in our cohort underwent neoadjuvant chemotherapy, whereas previous studies all excluded patients who received any chemotherapy (Table 4). PTGS2 is upregulated during inflammation and immune response activation, ${ }^{27}$ and as chemotherapeutic agents can stimulate this local immune response ${ }^{28}$ and are known to increase survival, ${ }^{29}$ it is possible PTGS2 expression is raised in patients in whom neoadjuvant chemotherapy has been the most effective.

Comparison with previous studies is limited, however, due to the variety of techniques used to score the staining in tumour specimens. There was substantial variation in low/high cohort proportions across studies (high expression proportion 
range $26.5 \%$ to $79.3 \%$ ), influenced by the use of different methods to calculate low/high expression cut-off values (Table 4). Also, although each of the former studies used staining intensity to score the tissue specimens, only three also took into account the proportion of cells staining positive to calculate an overall staining score. Furthermore, there was only one previous study which used the same H-score design and median score method to determine a cut-off value for low/high PTGS2 expression as in our study. ${ }^{18}$

When investigating recurrence-free survival there was suggestion of a protective effect (HR 0.85), however it was not statistically significant. A cause for the lack of a significant association observed is unclear. A potential explanation may be despite the large number of recurrences in the high PTGS2 group, these may be local relapses which could then be treated with radiotherapy, which would have much less of an impact on overall survival compared to those developing metastatic disease. Although some research has shown high PTGS2 expression is associated with increased risk of recurrence in patients with oesophageal adenocarcinoma, ${ }^{13,16,18}$ this was not observed in all studies. ${ }^{14}$ Moreover, only one of these studies investigated recurrence-free survival in patients with oesophageal adenocarcinoma, finding high PTGS2 expression was significantly associated with poor survival after three years of followup. ${ }^{13}$ Due to the paucity of evidence further cohort studies investigating recurrencefree survival are required.

Restricting the analysis to junctional tumours had little effect on the estimates observed for the total cohort, where high PTGS2 expression was associated with improved overall and cancer-specific survival. It is suggested cancer at the gastro- 
oesophageal junction is an independent disease from distal oesophageal and gastric cancer, in terms of epidemiology, risk factors and pathophysiology. ${ }^{30}$ Furthermore, the approach to surgical resection is different for junctional tumours and distal adenocarcinomas, where cancers at the gastro-oesophageal junction often involve partial or total gastrectomy in addition to oesophagectomy. ${ }^{31-33}$ Thus, subgroup analysis restricting to only gastro-oesophageal junction situated tumours created a more homogeneous group, showing these patients have similar associations between PTGS2 expression and prognosis as the whole study cohort.

A particular strength of our study is the population-based design as the study captures all oesophageal adenocarcinoma patients that underwent neoadjuvant chemotherapy followed by surgical resection, for curative intent, in Northern Ireland over the study time period. This is the first study to use a cohort of patients who underwent neoadjuvant chemotherapy, which is now standard for oesophageal adenocarcinoma management. ${ }^{31}$ Therefore, in contrast to all previous studies, our cohort more accurately reflects current practice. Although tumour heterogeneity is a recognised phenomenon that can affect molecular studies, we reduced its impact by using triplicate cores for each patient.

A limitation of this study is potential bias from confounding by unmeasured factors in the tumour microenvironment, which includes endogenous hormone activity, genomic variation and environmental exposures. ${ }^{34}$ Ideally, we would also have investigated PTGS2 expression in the diagnostic oesophageal cancer biopsies pre-chemotherapy, however there was not sufficient biopsy tissue available. Finally, our study is limited 
by a lack of data on use of inhibitors of the PTGS2 enzyme pathway, such as NSAID medication.

In conclusion, high PTGS2 expression in oesophageal adenocarcinoma tissue was associated with improved survival, contrasting previous evidence. There was no evidence of association between PTGS2 enzyme expression and recurrence-free survival. The associations observed may be due to influence from neoadjuvant chemotherapy. Further studies, with additional investigation of interactions between medication use, PTGS2 expression and prognosis from oesophageal adenocarcinoma would be of value to clarify these associations.

\section{Acknowledgements}

Authors ADS, UCMcM HGC and RCT conceived and designed the study. ADS, RCT and HGC were involved in data acquisition. ADS, JT and DTMcM analysed the tissue cores. ADS, UCMcM and HGC conducted statistical analysis. BTJ, CRC, RCT and HGC acted as study supervisors. ADS and HGC drafted the manuscript and all coauthors critically revised the manuscript and agreed the final manuscript.

\section{Funding}

This work was supported by the Gastrointestinal Cancer Research Charitable Fund administered by the Belfast Health and Social Care Trust. Tissue samples used in this research were received from the Northern Ireland Biobank which is funded by HSC Research and Development Division of the Public Health Agency in Northern Ireland and Cancer Research UK through the Belfast Cancer Research UK Centre and the 
Northern Ireland Experimental Cancer Medicine Centre; additional support was received from the Friends of the Cancer Centre. The Northern Ireland Molecular Pathology Laboratory has received funding from Cancer Research UK, the Friends of the Cancer Centre and the Sean Crummey Foundation. Author UCMcM received funding from the Northern Ireland Cancer Translational Research Group for this study. Author $\mathrm{HGC}$ is a co-investigator of the UKCRC Centre of Excellence for Public Health Northern Ireland. 


\section{REFERENCES}

1. World Health Organisation. GLOBOCAN 2012: Estimated Cancer Incidence, Mortality and Prevalence Worldwide; 2012. Available at: http://globocan.iarc.fr/Pages/fact_sheets_cancer.aspx [Accessed June 20, 2016].

2. Allemani C, Matsuda T, Carlo V Di, et al. Global surveillance of trends in cancer survival 2000-14 (CONCORD-3): analysis of individual records for 37 513025 patients diagnosed with one of 18 cancers from 322 population-based registries in 71 countries. Lancet 2018;391:1023-1075.

3. Rothwell PM, Fowkes FGR, Belch JF, et al. Effect of daily aspirin on longterm risk of death due to cancer: Analysis of individual patient data from randomised trials. Lancet 2011;377:31-41.

4. Williams CS, Mann M, Dubois RN. The role of cyclooxygenases in inflammation, cancer and development. Oncogene 1999;18:7908-7916.

5. Wang D, Dubois RN. Prostaglandins and cancer. Gut 2006;55:115-122.

6. Tsujii M, Dubois RN. Alterations in Cellular Adhesion and Apoptosis in Epithelial Cells Overexpressing Prostaglandin Endoperoxide Synthase 2. Cell 1995;83:493-501.

7. Kase S, Osaki M, Honjo S, et al. Expression of cyclo-oxygenase-2 is correlated with high intratumoral microvessel density and low apoptotic index in human esophageal squamous cell carcinomas. Virchows Arch 2003;442:129-35.

8. Zimmermann KC, Sarbia M, Weber AA, et al. Cyclooxygenase-2 expression in human esophageal carcinoma. Cancer Res 1999;59:198-204.

9. Shamma A, Yamamoto H, Doki Y, et al. Up-Regulation of Cyclooxygenase-2 in Squamous Carcinogenesis of the esophagus. Clin Cancer Res 2000;6:1229- 
1238.

10. Yu H-P, Shi L-Y, Lu W-H, et al. Expression of cyclooxygenase-2 (COX-2) in human esophageal cancer and in vitro inhibition by a specific COX-2 inhibitor, NS-398. J Gastroenterol Hepatol 2004;19:638-642.

11. Hu Z, Yang Y, Zhao Y, et al. The prognostic value of cyclooxygenase-2 expression in patients with esophageal cancer: evidence from a meta-analysis. Onco Targets Ther 2017;10:2893-2901.

12. Lagorce C, Paraf F, Vidaud D, et al. Cyclooxygenase-2 is expressed frequently and early in Barrett's oesophagus and associated adenocarcinoma. Histopathology 2003;42:457-465.

13. France M, Drew PA, Dodd T, et al. Cyclo-oxygenase-2 expression in esophageal adenocarcinoma as a determinant of clinical outcome following esophagectomy. Dis Esophagus 2004;17:136-140.

14. Prins MJD, Verhage RJJ, Kate FJW ten, et al. Cyclooxygenase isoenzyme-2 and vascular endothelial growth factor are associated with poor prognosis in esophageal adenocarcinoma. J Gastrointest Surg 2012;16:956-66.

15. Chen J, Wu F, Pei HL, et al. Analysis of the correlation between P53 and Cox2 expression and prognosis in esophageal cancer. Oncol Lett 2015;10:21972203.

16. Buskens CJ, Rees BP Van, Sivula A, et al. Prognostic significance of elevated cyclooxygenase 2 expression in patients with adenocarcinoma of the esophagus. Gastroenterology 2002;122:1800-1807.

17. Heeren P, Plukker J, Dullemen H Van, et al. Prognostic role of cyclooxygenase-2 expression in esophageal carcinoma. Cancer Lett $2005 ; 225: 283-289$. 
18. Bhandari P, Bateman AC, Mehta RL, et al. Prognostic significance of cyclooxygenase-2 (COX-2) expression in patients with surgically resectable adenocarcinoma of the oesophagus. BMC Cancer 2006;2:134.

19. Lewis C, McQuaid S, Hamilton PW, et al. Building a "Repository of Science": The importance of integrating biobanks within molecular pathology programmes. Eur J Cancer 2016;67:191-199.

20. Altman DG, McShane LM, Sauerbrei W, et al. Reporting Recommendations for Tumor Marker Prognostic Studies (REMARK): Explanation and Elaboration. PLoS Med 2012;9:e1001216.

21. Gray RT, Cantwell MM, Coleman HG, et al. Evaluation of PTGS2 Expression, PIK3CA Mutation, Aspirin Use and Colon Cancer Survival in a PopulationBased Cohort Study. Clin Transl Gastroenterol 2017;8:e91.

22. Blayney JK, Cairns L, Li G, et al. Glucose transporter 1 expression as a marker of prognosis in oesophageal adenocarcinoma. Oncotarget 2018;9:18518-18528.

23. Mccarty KS, Szabo E, Flowers JL, et al. Use of a Monoclonal Anti-Estrogen Receptor Antibody in the Immunohistochemical Evaluation of Human Tumors. Cancer Res 1986;46:4244-4248.

24. Siewert JR, Hölscher AH, Becker K, et al. Cardia cancer: attempt at a therapeutically relevant classification. Chirurg 1987;58:25-32.

25. Union for International Cancer Control. TNM: Classification of Malignant Tumours. Geneva, Switzerland; 2009.

26. Xi H, Baldus SE, Warnecke-Eberz U, et al. High cyclooxygenase-2 expression following neoadjuvant radiochemotherapy is associated with minor histopathologic response and poor prognosis in esophageal cancer. Clin Cancer Res 2005;11:8341-8347. 
27. Abdalla SI, Sanderson IR, Fitzgerald RC. Effect of inflammation on cyclooxygenase (COX)-2 expression in benign and malignant oesophageal cells. Carcinogenesis 2005;26:1627-1633.

28. Bracci L, Schiavoni G, Sistigu A, et al. Immune-based mechanisms of cytotoxic chemotherapy: implications for the design of novel and rationalebased combined treatments against cancer. Cell Death Differ 2013;21:15-25.

29. Hagen P van, Hulshof MCCM, Lanschot JJB van, et al. Preoperative Chemoradiotherapy for Esophageal or Junctional Cancer. N Engl J Med 2012;366:2074-2084.

30. Pastina M, Menna C, Andreetti C, et al. The esophagogastric junctional adenocarcinoma an increasing disease. J Thorac Dis 2017;9:1455-58.

31. Lordick F, Mariette C, Haustermans K, et al. Oesophageal cancer: ESMO Clinical Practice Guidelines for diagnosis, treatment and follow-up. Ann Oncol 2016;27:50-57.

32. Mariette C, Piessen G. Oesophageal cancer: how radical should surgery be? Eur J Surg Oncol 2012;38:210-3.

33. Mariette C, Piessen G, Briez N, et al. Oesophagogastric junction adenocarcinoma: which therapeutic approach? Lancet Oncol 2011;12:296-305.

34. Ogino S, Fuchs CS, Giovannucci E. How many molecular subtypes? Implications of the unique tumor principle in personalized medicine. Expert Rev Mol Diagn 2012;12:621-8. 
Table 1. Clinicopathological characteristics for patients with oesophageal adenocarcinoma by PTGS2 expression status

\begin{tabular}{|c|c|c|c|}
\hline & \multicolumn{2}{|c|}{ PTGS2 expression status } & \multirow[t]{2}{*}{$\mathrm{p}^{\mathrm{a}}$} \\
\hline & Low $(n=56)(41.1 \%)$ & High $(n=79)(58.9 \%)$ & \\
\hline \multicolumn{4}{|l|}{ Gender } \\
\hline Male & $45(80.4 \%)$ & $61(77.2 \%)$ & \multirow{2}{*}{0.66} \\
\hline Female & $11(19.6 \%)$ & $18(22.8 \%)$ & \\
\hline \multicolumn{4}{|c|}{ Age at Diagnosis (years) } \\
\hline Mean (SD) & $62.5(8.4)$ & $62.4(9.7)$ & \multirow{5}{*}{0.75} \\
\hline$<50$ & $7(12.5 \%)$ & $7(8.9 \%)$ & \\
\hline $50-59$ & $9(16.1 \%)$ & $28(35.4 \%)$ & \\
\hline $60-69$ & $27(48.2 \%)$ & $36(45.6 \%)$ & \\
\hline$>=70$ & $13(23.2 \%)$ & $18(22.8 \%)$ & \\
\hline \multicolumn{4}{|l|}{ Smoking Status } \\
\hline Never smoker & $14(25.0 \%)$ & $20(25.3 \%)$ & \multirow{4}{*}{0.51} \\
\hline Former smoker & $18(32.1 \%)$ & $17(21.5 \%)$ & \\
\hline Current smoker & $15(26.8 \%)$ & $34(43.0 \%)$ & \\
\hline Unknown & $9(16.1 \%)$ & $8(10.1 \%)$ & \\
\hline \multicolumn{4}{|c|}{ Alcohol Consumption } \\
\hline Never & $18(32.1 \%)$ & $25(31.6 \%)$ & \multirow{3}{*}{0.93} \\
\hline Ever use & $28(50.0 \%)$ & $43(54.4 \%)$ & \\
\hline Unknown & $10(17.9 \%)$ & $11(13.9 \%)$ & \\
\hline \multicolumn{4}{|l|}{ Primary Site } \\
\hline Lower third & $9(16.1 \%)$ & $12(15.2 \%)$ & \multirow{2}{*}{0.89} \\
\hline GOJ & $47(83.9 \%)$ & $67(84.8 \%)$ & \\
\hline $\mathrm{SC} 1$ & $27(48.2 \%)$ & $40(50.6 \%)$ & \multirow{4}{*}{0.95} \\
\hline $\mathrm{SC} 2$ & $15(26.8 \%)$ & $21(26.6 \%)$ & \\
\hline $\mathrm{SC} 3$ & $5(8.9 \%)$ & $6(7.6 \%)$ & \\
\hline Unknown & $9(16.1 \%)$ & $12(15.2 \%)$ & \\
\hline \multicolumn{4}{|l|}{ PET Responder } \\
\hline No & $15(26.8 \%)$ & $28(35.4 \%)$ & \multirow{3}{*}{0.02} \\
\hline Yes & $20(35.7 \%)$ & $38(48.1 \%)$ & \\
\hline Unknown & $21(37.5 \%)$ & $13(16.5 \%)$ & \\
\hline \multicolumn{4}{|l|}{ Lymphatic Vascular } \\
\hline \multicolumn{4}{|l|}{ Invasion } \\
\hline No & $16(28.6 \%)$ & $25(31.6 \%)$ & \multirow{3}{*}{0.64} \\
\hline Yes & $40(71.4 \%)$ & $53(67.1 \%)$ & \\
\hline Unknown & 0 & $1(1.3 \%)$ & \\
\hline \multicolumn{4}{|c|}{ Circumferential Resection } \\
\hline \multicolumn{4}{|l|}{ Margin Status } \\
\hline Negative & $29(51.8 \%)$ & $43(54.4 \%)$ & \multirow{3}{*}{0.65} \\
\hline Positive & $27(48.2 \%)$ & $35(44.3 \%)$ & \\
\hline Unknown & 0 & $1(1.3 \%)$ & \\
\hline Surgical T Stage & & & \\
\hline 1 & $2(3.6 \%)$ & $10(12.7 \%)$ & \\
\hline 2 & $12(21.4 \%)$ & $13(16.5 \%)$ & \\
\hline 3 & $40(71.4 \%)$ & $53(67.1 \%)$ & 0.50 \\
\hline 4 & $2(3.6 \%)$ & $2(2.5 \%)$ & \\
\hline Unknown & 0 & $1(1.3 \%)$ & \\
\hline Surgical N Stage & & & \\
\hline 0 & $14(25.0 \%)$ & $31(39.2 \%)$ & \\
\hline 1 & $14(25.0 \%)$ & $13(16.5 \%)$ & \\
\hline 2 & $12(21.4 \%)$ & $19(24.1 \%)$ & 0.24 \\
\hline 3 & $16(28.6 \%)$ & $16(20.3 \%)$ & \\
\hline
\end{tabular}

${ }^{a}$ Analysis using Chi squared

Abbreviations: $\mathrm{PET}=$ Positron Emission Tomography; GOJ = Gastro-oesophageal junction; $\mathrm{SC}$

$=$ Siewert Classification; $\mathrm{T}=$ Tumour; $\mathrm{N}=$ Nodal 
Table 2. Survival analysis for patients with oesophageal adenocarcinoma by PTGS2 expression status

\begin{tabular}{|c|c|c|c|c|c|c|}
\hline Survival & Events & Person-years & $\begin{array}{c}\text { Unadjusted HR } \\
(95 \% \mathrm{CI})\end{array}$ & $\mathrm{p}$ & $\begin{array}{l}\text { Adjusted HR }{ }^{\mathrm{a}} \\
(95 \% \mathrm{CI})\end{array}$ & $\mathrm{p}$ \\
\hline \multicolumn{7}{|l|}{ Overall $^{\mathrm{b}}$} \\
\hline Low expression & 37 & 138 & 1.00 (ref. cat.) & & 1.00 (ref. cat.) & \\
\hline High expression & 43 & 258 & $0.61(0.39,0.96)$ & 0.03 & $0.57(0.34,0.93)$ & 0.03 \\
\hline \multicolumn{7}{|l|}{ Cancer-specific ${ }^{c}$} \\
\hline Low expression & 35 & 136 & 1.00 (ref. cat.) & & 1.00 (ref. cat.) & \\
\hline High expression & 40 & 247 & $0.62(0.39,0.99)$ & 0.04 & $0.56(0.33,0.94)$ & 0.03 \\
\hline \multicolumn{7}{|l|}{ Recurrence-free $^{\mathrm{d}}$} \\
\hline Low expression & 38 & 118 & 1.00 (ref. cat.) & & 1.00 (ref. cat.) & \\
\hline High expression & 49 & 221 & $0.75(0.48,1.15)$ & 0.19 & $0.85(0.52,1.38)$ & 0.51 \\
\hline
\end{tabular}


Table 3. Sensitivity analysis: Analysis restricted to tumours at the gastro-oesophageal junction

\begin{tabular}{|c|c|c|c|c|c|c|}
\hline Survival & Events & Person-years & $\begin{array}{c}\text { Unadjusted HR } \\
(95 \% \mathrm{CI})\end{array}$ & $\mathrm{p}$ & $\begin{array}{l}\text { Adjusted HR }{ }^{\mathrm{a}} \\
(95 \% \mathrm{CI})\end{array}$ & $\mathrm{p}$ \\
\hline \multicolumn{7}{|l|}{ Overall $^{\mathrm{b}}$} \\
\hline Low expression & 32 & 113 & 1.00 (ref. cat.) & & 1.00 (ref. cat.) & \\
\hline High expression & 39 & 210 & $0.62(0.39,1.00)$ & 0.05 & $0.52(0.30,0.90)$ & 0.02 \\
\hline \multicolumn{7}{|l|}{ Cancer-specific $^{c}$} \\
\hline Low expression & 30 & 111 & 1.00 (ref. cat.) & & 1.00 (ref. cat.) & \\
\hline High expression & 36 & 199 & $0.64(0.39,1.04)$ & 0.07 & $0.50(0.28,0.88)$ & 0.02 \\
\hline \multicolumn{7}{|l|}{ Recurrence-free ${ }^{\mathrm{d}}$} \\
\hline Low expression & 33 & 97 & 1.00 (ref. cat.) & & 1.00 (ref. cat.) & \\
\hline High expression & 43 & 177 & $0.76(0.48,1.22)$ & 0.26 & $0.71(0.42,1.21)$ & 0.21 \\
\hline
\end{tabular}

${ }^{\mathrm{a} C o x}$ regression analysis adjusted for age at diagnosis, smoking, gender, surgical nodal staging, PET responder, circumferential resection margin status, tumour grade and vascular lymphatic invasion

${ }^{b}$ Events represents deaths from any cause

'Events represents deaths from oesophageal adenocarcinoma

${ }^{\mathrm{d}}$ Events represents recurrences or deaths 
Table 4. Previous studies of PTGS2 expression and survival in oesophageal adenocarcinoma cohorts

\begin{tabular}{|c|c|c|c|c|c|c|c|}
\hline \multirow[t]{2}{*}{ Study } & \multicolumn{2}{|c|}{ Number of patients } & \multirow[t]{2}{*}{ Antibody (dilution) } & \multirow{2}{*}{$\begin{array}{l}\text { Low/high expression } \\
\text { cut-off value } \\
\text { (range) }\end{array}$} & \multirow[t]{2}{*}{ Survival } & \multirow[t]{2}{*}{$\mathrm{HR}(95 \% \mathrm{CI})$} & \multirow[t]{2}{*}{$\mathrm{p}$} \\
\hline & $\begin{array}{c}\text { Low PTGS2 } \\
\text { expression }\end{array}$ & $\begin{array}{c}\text { High PTGS2 } \\
\text { expression }\end{array}$ & & & & & \\
\hline Buskens et al., 2002 & $30(20.7 \%)$ & $115(79.3 \%)$ & Mouse $(1: 200)$ & $\geq 2(0-3)^{a}$ & OS & $3.50(1.60,7.90)$ & NR \\
\hline Lagorce et al., 2003 & $45(68.2 \%)$ & $21(31.8 \%)$ & Goat $(1: 200)$ & $\geq 6(0-9)^{\mathrm{b}}$ & CSS & NR & 0.29 \\
\hline France et al., 2004 & $7(35.0 \%)$ & $13(65.0 \%)$ & Mouse (1:900) & $2(0-2)^{\mathrm{c}}$ & OS & NR & $0.03^{\mathrm{g}}$ \\
\hline Heeren et al., 2005 & $79(72.0 \%)$ & $31(28.0 \%)$ & Goat (1:50) & $\geq 3(0-9)^{\mathrm{d}}$ & OS & NR & $0.02^{\mathrm{g}}$ \\
\hline Bhandari et al., 2006 & $45(50.0 \%)$ & $45(50.0 \%)$ & Mouse (NR) & $\geq 200(0-300)^{\mathrm{e}}$ & OS & $2.91(1.78,4.76)$ & $<0.001$ \\
\hline Prins et al., 2012 & $108(73.5 \%)$ & $39(26.5 \%)$ & Mouse $(1: 100)$ & $3(0-3)^{\mathrm{f}}$ & $\mathrm{CSS}$ & $1.55(0.95,2.53)$ & 0.08 \\
\hline
\end{tabular}

Abbreviations: NR - Not reported; OS - Overall survival; CSS - Cancer-specific survival

${ }^{\mathrm{a}} 0=$ no staining; $1=$ weak intensity; $2=$ moderate-strong in $10-90 \%$ of cells; $3=$ strong in $>90 \%$ of cells

${ }^{\mathrm{b}} 0=$ no staining; $1=$ weak intensity; $2=$ medium intensity; $3=$ strong intensity; multiplied by score for $\%$ of cells stained $(0=0-4 \% ; 1=5-29 \% ; 2=30-59 \% ; 3=60-100 \%)$

${ }^{\mathrm{c}} 0=$ no staining; $1=$ light $/$ moderate intensity or less than $50 \%$ of cells stain; $2=$ strong intensity $\& 100 \%$ of cells stain

${ }^{\mathrm{d}} 0=$ no staining; $1=$ weak intensity; $2=$ medium intensity; $3=$ strong intensity; multiplied by score for $\%$ of cells stained $(0=0-4 \% ; 1=5-29 \% ; 2=30-59 \% ; 3=60-100 \%)$

${ }^{\mathrm{e}} 0=$ no staining; $1=$ weak intensity; $2=$ moderate intensity; $3=$ strong intensity; multiplied by score for $\%$ of cells stained. Median value used for cut-off

${ }^{\mathrm{f}} 0=$ no staining; $1=$ weak intensity; $2=$ moderate intensity; $3=$ strong intensity

gSignificant for poor survival 


\section{Figure legend}

Figure 1. PTGS2 IHC staining in oesophageal adenocarcinoma tissue microarray core samples.

A: no staining [0]; B: weak staining [1]; C: moderate staining [2]; D: strong staining [3]

Figure 2. Flow chart of the study. 
Figure 1. PTGS2 IHC staining in oesophageal adenocarcinoma tissue microarray core samples.
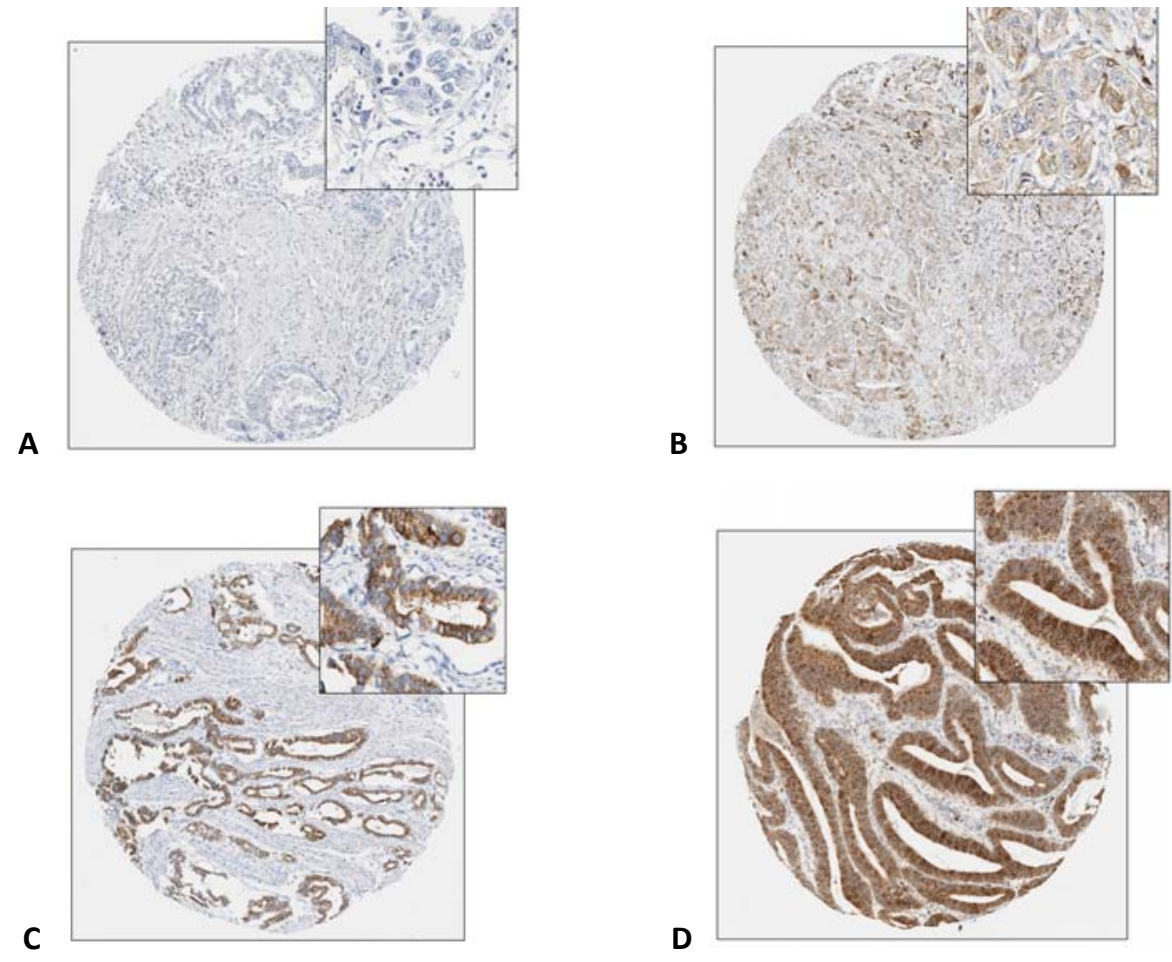
Figure 2. Flow chart of the study.

\begin{tabular}{|c|c|}
\hline $\begin{array}{l}\text { Number patients diagnosed with } \\
\text { oesophageal adenocarcinoma } \\
\text { 2004-2012 } \\
\qquad n=158\end{array}$ & \\
\hline & $\begin{array}{l}\text { Patients excluded due to: } \\
\text { absence of tumour in all three } \\
\text { core samples } \\
\qquad \mathrm{n}=15 \\
\text { insufficient } \\
\text { clinicopathological data }\end{array}$ \\
\hline & $\begin{array}{l}\text { complete response following } \\
\text { neoadjuvant chemotherapy } \\
\qquad n=3 \\
\text { metastasis present at the time } \\
\text { of surgery } \\
\qquad n=1\end{array}$ \\
\hline $\begin{array}{l}\text { Number patients remaining for the } \\
\text { main analysis } \\
\qquad n=135\end{array}$ & \\
\hline
\end{tabular}

